Original Research Article

\title{
Comparative study of prevalence of burn out among medical students from two medical colleges in Eastern India
}

\author{
Tapas Bera, Ananya Mandal*
}

Department of Pharmacology, Nil Ratan Sircar Medical College and Hospital, Kolkata, West Bengal, India

Received: 26 April 2019

Accepted: 30 April 2019

\section{*Correspondence to: \\ Dr. Ananya Mandal, Email: drananyamandal@ gmail.com}

Copyright: (C) the author(s), publisher and licensee Medip Academy. This is an open-access article distributed under the terms of the Creative Commons Attribution Non-Commercial License, which permits unrestricted non-commercial use, distribution, and reproduction in any medium, provided the original work is properly cited.

\begin{abstract}
Background: Emotional exhaustion, and reduced perception of personal accomplishment is commonly defined as burn out syndrome. This may develop when there is significant stress without adequate support and resources in the face of work overload, as commonly happens with physicians and undergraduate medical students.

Methods: This work attempted to study the level of burn out among all the second professional medical students in two different medical colleges and compare the trends of an urban medical college with a college in the outskirts of the city. 278 students from two medical colleges participated in the study wherein they were given standard questionnaires for assessment of stress, support, satisfaction and control parameters.

Results: Overall 169 students of the 278 (60.79\%) interviewed had scores correlating with burn out. Both college students showed burnout in the various parameters individually like stress, lack of support, dissatisfaction, lack of control and perception of success. There was a significantly greater prevalence of burn out scores among students in the city college (123 students or 60.84\%) compared to those studying in the rural medical college (46 students or $41.07 \%)(\mathrm{p} \leq 0.05)$ Conclusions: Burn out syndrome was more prevalent among city students compared to rural students. Individual as well as organizational interventions need to be targeted to prevent burnout among medical students.
\end{abstract}

Keywords: Burn out, Medical students, Stress

\section{INTRODUCTION}

Burn out is common among physicians and those in other stressful occupations. Medical studies especially demands a huge amount of physical and psychological efforts. This can lead to a syndrome of Burnout, which is described as a state of emotional exhaustion, depersonalization, and reduced personal accomplishment. ${ }^{1}$ Burnout can develop among healthcare providers and thus can become an important area in patient healthcare delivery. ${ }^{2-4}$ It is more likely to occur when there is significant stress without adequate support and resources in the face of work overload. This is commonly seen among physicians and undergraduate medical students. With burnout there also a high degree of failure in adequate patient care and there is a rise in unprofessional conduct. Physicians do not seek the kind of professional help for themselves, as they provide for their patients. ${ }^{5-8}$ Medical students seem to adopt a similar behavior. ${ }^{9,10}$

Prevalence rate of Burnout for medical students vary. Interview-based studies show $10-12 \%$ one-year prevalence of depression in an American sample, reported twenty years ago. ${ }^{11}$ Recently in a UK sample, psychiatric morbidity was found in $16 \%$ of medical students. ${ }^{12}$ Based on self-ratings, a prevalence rate of $14-24 \%$ (BDI scores) of depression have been reported. ${ }^{13-15}$ In a longitudinal 
sample 1222-36\% (GHQ-12) of psychiatric cases were found. A study of Swedish university students shows $27 \%$ of depression during the previous academic year. ${ }^{16}$ There are no studies that look at burn out prevalence and mental distress among colleges of Eastern India. Further there have been no comparative studies to look at the differences among prevalence of burn out among students studying in a college situated in a metropolitan city and one situated in rural Bengal.

Burn out especially among students who deal with and communicate with patients is important. From the patient's point of view, the doctor might appear aloof, uncaring, cynical or critical. This burnout also helps in growth of depersonalization. Burn out also leads to a significantly decreased satisfaction with life and perception of value of accomplishments. ${ }^{1}$ Thus, added together the standard scales of assessment of a three-dimensional syndrome of burnout could predict the outcome in most studied participants.

The main aim of this study was to determine the presence of clinically significant psychiatric morbidity at the initial stage of clinical training and to examine its relation to burnout levels in two different medical colleges in eastern India. We also aimed to compare the relative prevalence of burn out among the students of the two colleges.

\section{METHODS}

\section{The Participants and procedures:}

All students $(\mathrm{n}=278 ; 44.24 \%$ females $)$ included in the study from the two different medical colleges (College 1 and 2) were given a questionnaire. Written informed consent was obtained for the study. Students identified with clinically significant suffering were suggested counselling and appropriate help.

\section{Measures}

The questionnaire contained items on previous and concurrent psychological or personal problems. Four Domains of measurements - stressor, support, satisfaction and control were tested using Likert Scale. ${ }^{12-14}$ Each Domain included six or seven questions that participants had to answer from which the mean is drawn. Burnout was said to be present if the composite score was less than or equal to 44. Stress was assessed to be present in case of scores less than or equal to 14. Similarly, support was said to be dissatisfactory if the scores were less than or equal to14. Satisfaction scores 12 or less describe lack of satisfaction and lack of sense of control. Accomplishment assessed by a score of 4 or less. The questionnaire is shown in Annexure.

\section{Statistical analysis}

Statistical analysis was done using tools of descriptive statistics using Microsoft Excel. Comparison of the two groups was made using unpaired t test and a $\mathrm{p}$ value of less than 0.05 was considered to be significant.

\section{RESULTS}

Our study reveals that on an average, there is significantly high perceived stress, lack of support, lack of control and dissatisfaction among the students of 2nd professional medical students of two medical colleges. Of these, (Nilratan Sircar Medical College, Kolkata- College 1) is located in a metropolitan city while the other (Bankura Sammilani Medical College, Bankura- College 2) is located in the periphery of the city (around $250 \mathrm{~km}$ away from the city). On an average, burn out was observed to a lesser degree in the medical college in the suburbs compared to those in the metropolitan city $(\mathrm{p} \leq 0.05)$. Overall 169 students of the 278 (60.79\%), interviewed had scores correlating with burn out. The results are depicted in Table 1. The prevalence of burn out among the two different colleges is depicted graphically in Figure 1. Since there have been no similar studies in India; we anticipate future studies would support our findings.

Table 1: Burn out scores of students of 2 medical colleges in Eastern India.

\begin{tabular}{|llll|}
\hline College & \multicolumn{2}{c|}{$\mathbf{1}$} & $\mathbf{2}$ \\
\hline Domain & Score & \\
\hline Total students & & 250 & 150 \\
\hline Surveyed students & & 166 & 112 \\
\hline Female (\%) & & $44.57(74)$ & $43.75(49)$ \\
\hline Average age (years) & & 19.1 & 19.42 \\
\hline Stress score* & $\leq 14$ & 12.49 & 7.43 \\
\hline Support score & $\geq 14$ & 6.57 & 9.89 \\
\hline Satisfaction score** & $\geq 12$ & 9.1 & 8.93 \\
\hline $\begin{array}{l}\text { Control and } \\
\text { accomplishment } \\
\text { score }\end{array}$ & $\geq 04$ & 4.52 & 5.89 \\
\hline $\begin{array}{l}\text { Burnout Score } \\
\text { (Prevalence) }\end{array}$ & $\leq 44$ & $\begin{array}{l}60.84 \% \\
(123)\end{array}$ & $\begin{array}{l}41.07 \% \\
(46)\end{array}$ \\
\hline
\end{tabular}

*High stress denotes Parental pressure and financial difficulties ** High satisfaction denotes support from friends and Academic success

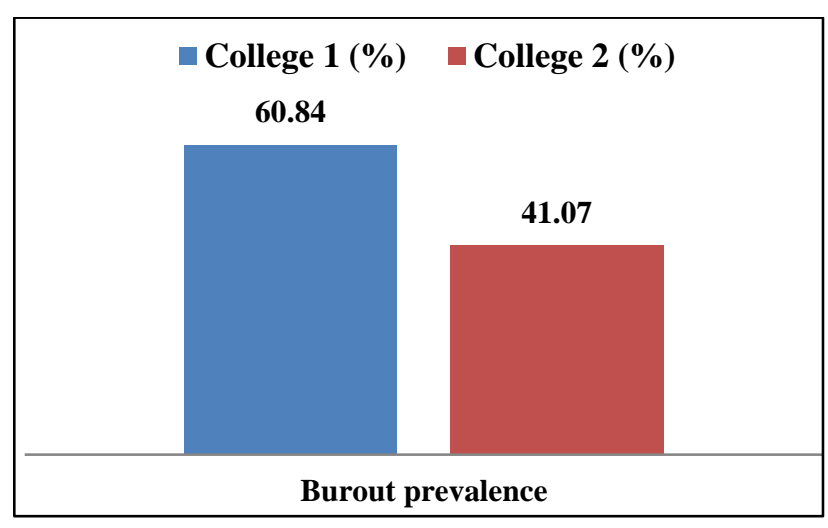

Figure 1: Relative prevalence of burn out in the two medical college students. 


\section{DISCUSSION}

Adequate emotional and other forms of support is essential for successfully completing medical studies. Loss of balance and feeling of emotional exhaustion is common among medical students since the beginning of this rigorous course.

Our study showed that the average age of the participants was similar. Overall 169 students of the 278 (60.79\%), interviewed had scores correlating with burn out. This is higher than the reported statistics from previous studies where prevalence of burnout and psychiatric co morbidities ranged from 6 to $27 \% .^{11-14}$

There was no statistically significant difference in the support scores. While stress perception was high among urban students, it was low among the rural students. Support was low for both groups. The difference was not statistically significant. This meant that the peer and parental pressure as well as financial pressure felt by both sets of students was similar. Control and accomplishment as well as Satisfaction score too did not differ significantly among the two groups significantly. Burn out prevalence however differed markedly among the two groups.

During both preclinical and paraclinical years, the setting is one of overwhelming work (facts to be learned) with limited resources (time and memory). The prevalence of burnout increases over the initial years, indicating the development of burnout from preclinical medical education and continuing into clinical years.

To reduce these effects focus must be to reduce stress, time of work and improve resiliency and the work environment. Each of the items studied here deals with burn out. To help prevent burnout there may be several strategies medical colleges can take to diminish stressors. This includes regular inclusion of sports and extracurricular activities for intermingling of students and also reduction of stress.

Deemphasizing grades and reducing summative exams could be another approach. Counselling programs may help students with the uncertainty of future plans, as well as helping support their decision in choice of specialties.

There have been studies showing that even one symptom of burn out could have a negative impact on the teaching learning process of medical students. It could lead to fatigue, depression, drowsiness, inattention, eating disorders, migraine, emotional instability and use of illicit drugs. Pedagogical teaching in the first couple of years of medical studies could be one of the reasons. ${ }^{12-18}$ Experts have said that stress when managed better could help provide motivation without negative effects. Thus, one remedy might be methods to help students better manage stress with the help of counselling in the pre- and paraclinical years in medical colleges.
Our study is limited by several factors. One of the major problems was response bias. Students with burnout might be more or less likely to respond to the survey. This study is cross-sectional rather than longitudinal Further studies that are interview based and can identify other factors that contribute to the differences in burn out in the two different set ups could help determine the cause of burn out and help address them.

\section{CONCLUSION}

Interventions addressing the mental health of medical students might be directed towards those revealing depressive symptoms already during their first year of medical school. Interventions on the part of the faculty and organizations could help prevent burnout among medical students.

\section{Funding: No funding sources}

Conflict of interest: None declared

Ethical approval: The study was approved by the Institutional Ethics Committee

\section{REFERENCES}

1. Maslach C, Jackson SE, Lieter MP. Maslach Burnout Inventory Manual. $3^{\text {rd }}$ Ed; Palo Alto, CA: Consulting Psychologists Press; 1996.

2. Pöhlmann K, Jonas I, Ruf S, Harzer W. Stress, burnout and health in the clinical period of dental education. Euro J Dental Educat. 2005 May;9(2):78-84.

3. Rosvold EO, Bjertness E: Physicians who do not take sick leave: hazardous heroes? Scand J Public Health. 2001 Jan;29(1):71-5.

4. Rosvold EO, Bjertness E. Illness behaviour among Norwegian physicians. Scand J Public Health. 2002 Apr;30(2):125-32.

5. Toyry S, Rasanen K, Kujala S, Aarimaa M, Juntunen J, Kalimo R, et al. Self-reported health, illness, and self-care among finnish physicians: a national survey. Arch Fam Med. 2000 Nov 1;9(10):1079.

6. Tyssen R, Rovik JO, Vaglum P, Gronvold NT, Ekeberg O. Help-seeking for mental health problems among young physicians: is it the most ill that seeks help?. A longitudinal and nationwide study. Soc Psychiatry Psychiatr Epidemiol. 2004 Dec 1;39(12):989-93.

7. Chew-Graham CA, Rogers A, Yassin N. 'I wouldn't want it on my CV or their records': medical students' experiences of help seeking for mental health problems. Med Educ. 2003 Oct;37(10):873-80.

8. Hooper C, Meakin R, Jones M. Where students go when they are ill: how medical students access health care. Med Educ. 2005 Jun;39(6):588-93.

9. Kumar S, Dagli RJ, Mathur A, Jan M, Prabu D, Kulkarni s. Perceived sources of stress among Indian Dental students. Eur J Dent. 2009 Feb;13(1):39-45.

10. Guthrie E, Black D, Bagalkote H, Shaw C, Campbell M, Creed F. Psychological stress and burnout in 
medical students: a five-year prospective longitudinal study. J R Soc Med. 1998 May;91(5):237-43.

11. Tjia J, Givens JL. Shea JA: Factors associated with undertreatment of medical student depression. J Am Coll Health. 2005;53:219-24.

12. Givens JL, Tjia J: Depressed medical students' use of mental health services and barriers to use. Acad Med 2002 Sep 1;77(9):918-21.

13. Clark DC, Zeldow PB: Vicissitudes of depressed mood during four years of medical school. JAMA. 1988 Nov 4;260(17):2521-8.

14. Dahlin ME, Runeson B. Burnout and psychiatric morbidity among medical students entering clinical training: a three-year prospective questionnaire and interview-based study. BMC Medical Education. 2007 Dec;7(1):6-13.

15. Boni RAS, Paiva CE, Olivieira MA, Lucchetti G, Fregnani JHTG, Paiva BSR et al. Burnout among medical students during the first years of undergraduate school: Prevalence and associated factors. PLoS One. 2018 Mar 7;13(3): e0191746.
16. Ishak W, Nikravesh R, Lederer S, Perry R, Ogunyemi $\mathrm{D}$, Bernstein $\mathrm{C}$, et al. Burnout in medical students: a systematic review. Clin Teach. 2013 Aug;10(4):2425.

17. Dyrbye LN, West CP, Satele D, Boone S, Tan L, Sloan J, et al. Burnout Among U.S. Medical Students, Residents, and Early Career Physicians Relative to the General U.S. Population. Academic Medicine. 2014 March 1;89(3):443-51.

18. Frajerman A, Morvan Y, Krebs MO, Gorwood P, Chaumette B. Burnout in medical students before residency: A systematic review and meta-analysis. European Psychiatry. 2019 Jan 1;55:36-42.

Cite this article as: Bera T, Mandal A. Comparative study of prevalence of burn out among medical students from two medical colleges in Eastern India. Int J Basic Clin Pharmacol 2019;8:1238-42. 
Annexure: Questionnaire to check burn-out in medical students.

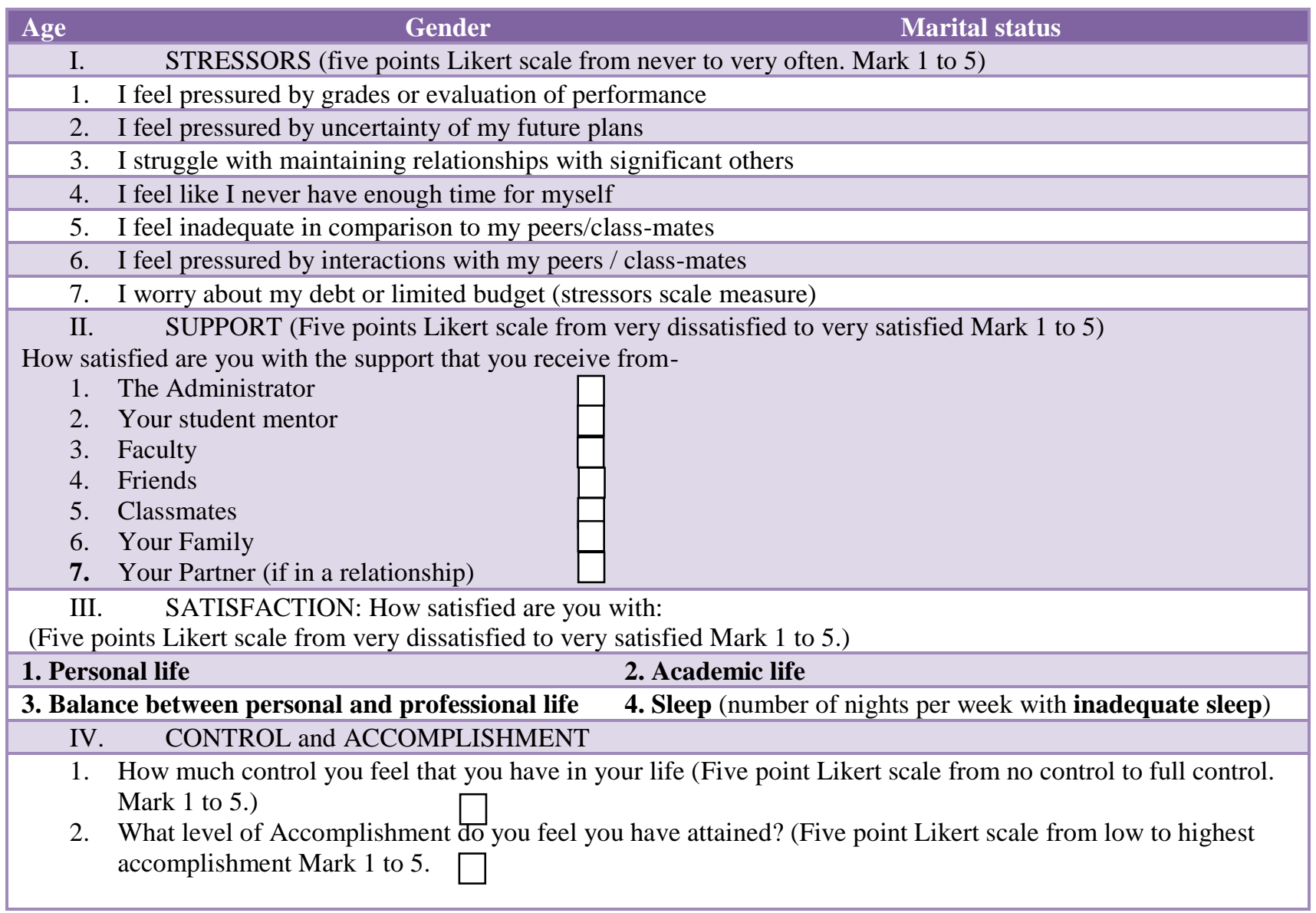

